\title{
Estimativa da produtividade de arroz irrigado em função da radiação solar global e da temperatura mínima do ar
}

\author{
Rice yield estimates based on global solar radiation and minimum air temperature
}

\author{
Silvio Steinmetz ${ }^{\text {I }}$ Alexandre Nunes Deibler ${ }^{\text {II }}$ João Baptista da Silva ${ }^{\text {II }}$
}

\section{RESUMO}

Considerando-se a importância da produção do arroz irrigado no Estado do Rio Grande do Sul e que o seu desempenho é influenciado pelas condições meteorológicas, o objetivo deste trabalho foi estimar a produtividade de grãos dessa cultura em função da radiação solar global e da temperatura mínima do ar, usando procedimentos de análise de regressão linear simples e múltipla. Realizou-se um experimento de campo, em Capão do Leão, RS, durante três anos agrícolas. Empregaram-se, em cada ano agrícola, seis datas de semeadura e oito cultivares de diferentes grupos de comprimento de ciclo. Dez colmos principais de cada cultivar foram marcados, para determinarem-se os principais estádios de desenvolvimento. A variável dependente $(Y)$ foi a média da produtividade de quatro repetições, de cada época de semeadura, e as variáveis independentes foram: a média da radiação solar global $\left(X_{1}\right)$, a média da temperatura mínima do ar $\left(X_{2}\right)$ e a média da temperatura mínima do ar elevada ao quadrado $\left(X_{3}\right)$, computadas em quatro períodos de desenvolvimento da planta para a radiação solar global e em três períodos para a temperatura mínima do ar. A maioria das variáveis, quando testadas isoladamente, apresentou uma relação linear significativa com a produtividade, mas os coeficientes de determinação $\left(r^{2}\right)$ foram mais elevados nas regressões lineares múltiplas envolvendo as principais variáveis. Modelos de regressão que utilizam como variáveis preditoras a radiação solar global e a temperatura mínima do ar, em diferentes períodos de desenvolvimento da planta, mostram-se adequados para a estimativa da produtividade de grãos de arroz irrigado.

Palavras-chave: Oryza sativa L., rendimento de grãos, modelo de regressão, estádio de desenvolvimento da planta.

\begin{abstract}
Considering the importance of irrigated rice production in the State of Rio Grande do Sul and that its performance is influenced by the weather conditions, the objective of this study was to estimate the grain yield of this crop as a function of global solar radiation and minimum air temperature using procedures of linear simple and multiple regression. A field experiment was conducted at the district of Capão do Leão, State of Rio Grande do Sul, Brazil, during three growing seasons. Six sowing dates and eight cultivars of distinct groups of cycle lengths were used in each crop season. Ten main culms of each cultivar were marked to determine the main stages of development. The dependent variable (Y) was the average grain yield of four repetitions of each sowing date and the independent variables were: the average of global solar radiation $\left(X_{1}\right)$, the average minimum air temperature $\left(X_{2}\right)$ and the average of squared minimum air temperature $\left(X_{3}\right)$, computed for four periods of plant development for global solar radiation and for three periods for minimum air temperature. Most of the variables, when tested isolately, presented a significant linear relationship with grain yield, but the coefficients of determination $\left(r^{2}\right)$ were higher in multiple linear regressions involving the main variables. Regression models that use global solar radiation and minimum air temperature in distinct physiological periods of plant development as predicting variables, are suitable for estimating grain yields of irrigated rice.
\end{abstract}

Key words: Oryza sativa $L$., grain yield, regression model, plant development stage.

\footnotetext{
'Laboratório de Agrometeorologia, Embrapa Clima Temperado, BR 392 Km 78, CP 403, 96001-970, Pelotas, RS, Brasil. E-mail: silvio.steinmetz@embrapa.br. Autor para correspondência.

"Universidade da Região da Campanha (URCAMP), Bagé, RS, Brasil.

IIInstituto de Física e Matemática, Universidade Federal de Pelotas (UFPel), Pelotas, RS, Brasil.
} 


\section{INTRODUÇÃO}

O Estado do Rio Grande do Sul é o maior produtor de arroz irrigado do Brasil, tendo contribuído, nas safras 2009/10 a 2011/12, com 64\% da produção nacional (CONAB, 2012). Apesar dos altos índices de produtividade - média de $7,2 \mathrm{t} \mathrm{ha}^{-1}$ nessas três safras -, ocorrem, em alguns anos, quedas na produtividade, causadas, fundamentalmente, por condições climáticas adversas tais como baixos níveis de radiação solar e baixas temperaturas do ar durante os períodos críticos da planta (MOTA, 1994; STEINMETZ \& BRAGA, 2001). A produtividade de grãos é influenciada pela disponibilidade de radiação solar, principalmente nas fases reprodutiva (da diferenciação da panícula à floração) e de maturação (da floração à maturação fisiológica do grão) (STANSEL, 1975; YOSHIDA \& PARAO, 1976). A produtividade também é afetada pela ocorrência de baixas temperaturas do ar, principalmente nas fases de pré-floração (microsporogênese) e floração, devido à esterilidade de espiguetas (SATAKE, 1976; TERRES \& GALLI, 1985). A faixa crítica de temperatura para induzir esterilidade no arroz é de $15^{\circ} \mathrm{C}$ a $17^{\circ} \mathrm{C}$, para os genótipos altamente tolerantes ao frio, e de $17^{\circ} \mathrm{C}$ e $19^{\circ} \mathrm{C}$, para os de maior sensibilidade (NISHIYAMA et al., 1969, citado por SATAKE, 1976).

Dentre os modelos usados para estimar a produtividade, o método estatístico ou de correlação, apesar de algumas limitações, tem as vantagens de obter valores razoáveis de produtividade sem o uso de dados biológicos e de estabelecer os intervalos de confiança para as variáveis estimadas (BAKEMA \& JANSEN, 1986). Esse método tem sido usado para estimar a produtividade de grãos de arroz em diferentes regiões do mundo, como no Japão, considerando horas de insolação durante o período de pré-floração e enchimento de grão (MURATA, 1975), em diferentes localidades da África, Ásia, América Latina e Oceania, utilizando a radiação solar global e a temperatura mínima do ar nos períodos de pré e pós-floração (SESHU \& CADY, 1984), e na Índia, usando, dentre outras variáveis, a radiação solar, a insolação, a temperatura mínima do ar e a temperatura máxima do ar (KANDIANNAN et al., 2002).

No Brasil, esse método também foi usado em diferentes localidades, como em Pindamonhangaba (SP), considerando a temperatura do ar e a radiação solar no período de 10 dias antes a 30 dias após a floração (PEDRO JÚNIOR et al., 1995); em Pelotas e Capão do Leão (RS), utilizando a radiação solar global média diária em fevereiro e março e o número de horas com temperaturas iguais ou inferiores a $15^{\circ} \mathrm{C}$ em fevereiro e março (MOTA, 1994); nas diferentes regiões produtoras do Rio Grande do Sul, utilizando a insolação e temperatura mínima do ar (CARMONA et al., 2002)e, mais recentemente, com dados de experimentos de épocas de semeadura, em Cachoeirinha (RS), usando a temperatura mínima do ar, no período de 5 dias antes a 15 dias após a floração, e a radiação solar, de 21 dias antes a 21 dias após a floração (DEIBLER et al., 2007).

A análise da literatura indica que, em condições experimentais, a maioria dos trabalhos considerou a influência dos elementos meteorológicos em determinados períodos fixos (30 dias após a floração, por exemplo), portanto, diferente do que está sendo proposto neste trabalho, que considerou os principais períodos críticos da planta à temperatura mínima do ar e à radiação solar, e que esses períodos críticos foram definidos a partir da determinação, em campo, dos estádios de desenvolvimento da planta.

O presente trabalho teve por objetivo estimar a produtividade de grãos de arroz irrigado em função da radiação solar global e da temperatura mínima do ar, em diferentes períodos de desenvolvimento da planta, usando procedimentos de análise de regressão linear simples e múltipla.

\section{MATERIAL E MÉTODOS}

O experimento de campo foi realizado na área da Estação Experimental Terras Baixas (ETB) da Embrapa Clima Temperado, em Capão do Leão, RS (latitude de $31^{\circ} 52^{\prime} \mathrm{S}$; longitude de $52^{\circ} 21^{\prime} \mathrm{W}$ e altitude de $13 \mathrm{~m}$ ), durante três anos agrícolas (2004/05, 2005/06 e 2006/07). O clima local, segundo a classificação climática de Köppen, é do tipo Cfa, que corresponde ao subtropical úmido, com verões quentes e sem estação seca definida (WREGE et al., 2011). O solo da área experimental é classificado como Planossolo Háplico eutrófico típico (SANTOS et al., 2006).

Implantaram-se seis épocas de semeadura em cada ano agrícola: (1) 2004/05: 5/10, 22/10, 4/11,23/ 11 e 7/12; (2): 2005/06: 12/10, 1/11, 14/11, 28/11, 12/12 e 28/12, e (3) 2006/07: 2/10, 14/10,30/10,13/11,27/11 e $11 /$ 12. As épocas de semeadura foram escolhidas para expor as plantas a condições meteorológicas distintas e estavam próximas do período recomendado de semeadura, que era a partir de 11 de outubro, para cultivares tardias, e até 10 de dezembro, para cultivares muito precoces (SOCIEDADE, 2005).

Das doze cultivares ou linhagens utilizadas em cada safra agrícola, foram consideradas para o trabalho oito cultivares de arroz irrigado, sendo uma de ciclo muito precoce ('BRS Atalanta'), três de ciclo precoce ('BRS-6 Chui', 'BRS Querência' e 'BRS Firmeza') e quatro de ciclo médio ('BR-IRGA 410', 'BRS Pelota', 'BRS-7 Taim' e 'BRS Fronteira'). O delineamento experimental foi em blocos ao acaso com quatro repetições. As parcelas (5,0m de comprimento e 
$1,58 \mathrm{~m}$ de largura) constaram de nove linhas espaçadas de $17,5 \mathrm{~cm}$. Adensidade de semeadura foi de 80 sementes aptas por metro linear. A área útil constou de cinco linhas de 4,0m de comprimento. As doses de nitrogênio, fósforo e potássio, para expectativa de produtividade superior a $9 \mathrm{t} \mathrm{ha}^{-1}$, a forma de aplicação, bem como os demais tratos culturais seguiram as recomendações da SOCIEDADE (2005). A lâmina de água foi mantida a uma altura média entre $5 \mathrm{e} 10 \mathrm{~cm}$. A produtividade de grãos foi obtida a partir da média de quatro repetições.

Dez plantas (colmo principal) de cada cultivar foram marcadas, em uma repetição, e tiveram o desenvolvimento acompanhado durante todo o ciclo, caracterizando-se cada estádio de acordo com a escala proposta por COUNCE et al. (2000). A partir das observações realizadas três vezes por semana, foram obtidas as datas médias de cada estádio, que foram usadas para definir os períodos críticos à radiação solar e às baixas temperaturas do ar.

As variáveis meteorológicas foram a radiação solar global média diária $\left(\mathrm{cal} \mathrm{cm}^{-2} \mathrm{dia}^{-1}\right)$ e a temperatura mínima diária do $\operatorname{ar}\left({ }^{\circ} \mathrm{C}\right)$, obtidas na Estação Agroclimatológica de Capão do Leão, RS, mantida através do Convênio EMBRAPA/UFPel/INMET.

Para estabelecer a influência das variáveis preditoras (meteorológicas) na produtividade de grãos, empregou-se a análise de regressão linear simples e múltipla, em que a variável dependente (Y) foi a média da produtividade de quatro repetições de cada época de semeadura, para cada cultivar ou grupo de cultivares, e as variáveis independentes foram: a média da radiação solar global $\left(\mathrm{X}_{1}\right)$, a média da temperatura mínima do ar $\left(X_{2}\right)$ e a média da temperatura mínima do ar elevada ao quadrado $\left(\mathrm{X}_{3}\right)$, computadas nos distintos períodos fenológicos, a saber:
- radiação solar global: da emergência das plântulas até a diferenciação da panícula $\left(\mathrm{R}_{1}\right)$; da diferenciação da panícula ao início da floração ou da antese $\left(\mathrm{R}_{2}\right)$; do início da floração à maturação completa dos grãos $\left(\mathrm{R}_{3}\right)$; e da emergência à maturação completa dos grãos $\left(\mathrm{R}_{4}\right)$; - temperatura mínima: da diferenciação da panícula à formação do colar da folha bandeira $\left(\mathrm{T}_{1}\right)$; da formação do colar da folha bandeira ao início da floração $\left(\mathrm{T}_{2}\right)$; do início da floração à maturação completa dos grãos $\left(\mathrm{T}_{3}\right)$. Os valores de temperatura mínima do ar obtidos em todos os períodos estabelecidos também foram elevados ao quadrado, com o objetivo de testar o efeito curvilinear na produtividade (SESHU \& CADY, 1984). As análises foram realizadas pelo Sistema de Análise Estatística para Microcomputadores - SANEST (ZONTA\& MACHADO, 1984).

Antes da realização das análises de regressão linear múltipla, identificaram-se, através de análises de regressão simples, as variáveis preditoras com maior influência na produtividade de grãos e, a partir daí, estabeleceram-se as regressões múltiplas. Posteriormente, foi acrescentada ao modelo a terceira variável preditora, (temperatura mínima média elevada ao quadrado), obtida nos distintos períodos de desenvolvimento da planta.

\section{RESULTADOS E DISCUSSÃO}

As variáveis $\mathrm{R}_{1}$ (radiação solar global média da emergência até a diferenciação da panícula) e $T_{3}$ (média da temperatura mínima do ar ocorrida do início da floração até a maturação dos grãos) mostraram-se como as mais importantes na explicação da variação da produtividade de grãos, para o grupo de cultivares precoce (Tabela 1). Para as cultivares do grupo médio

Tabela 1 - Análise de regressão linear simples e múltipla entre a produtividade média de grãos de cultivares de arroz irrigado de ciclo precoce, a radiação solar global $(\mathrm{R})$ e a temperatura mínima do ar (T), em diferentes períodos do ciclo da planta, nas safras 2004/05, 2005/06 e 2006/07. Capão do Leão, RS.

\begin{tabular}{lll}
\hline Variável & Modelo & $\mathrm{r}^{2}$ \\
\hline $\mathrm{R}_{1}$ & $\mathrm{Y}=-16,466+0,044 \mathrm{R}_{1}$ & $0,65^{* *}$ \\
$\mathrm{R}_{2}$ & $\mathrm{Y}=1,472+0,009 \mathrm{R}_{2}$ & $0,25^{*}$ \\
$\mathrm{R}_{3}$ & $\mathrm{Y}=3,320+0,007 \mathrm{R}_{3}$ & $0,34^{*}$ \\
$\mathrm{R}_{4}$ & $\mathrm{Y}=-0,063+0,013 \mathrm{R}_{4}$ & $0,40^{* *}$ \\
$\mathrm{~T}_{1}$ & $\mathrm{Y}=1,597+0,240 \mathrm{~T}_{1}$ & $0,06^{\text {n.s. }}$ \\
$\mathrm{T}_{2}$ & $\mathrm{Y}=18,427-0,661 \mathrm{~T}_{2}$ & $0,20^{\text {n.s. }}$ \\
$\mathrm{T}_{3}$ & $\mathrm{Y}=-7,667+0,758 \mathrm{~T}_{3}$ & $0,46^{* *}$ \\
$\mathrm{R}_{1}, \mathrm{~T}_{3}$ & $\mathrm{Y}=-17,805+0,0344 \mathrm{R}_{1}+0,352 \mathrm{~T}_{3}$ & $0,72^{* *}$ \\
$\mathrm{R}_{1}, \mathrm{~T}_{3}, \mathrm{~T}_{6}$ & $\mathrm{Y}=31,209+0,0301 \mathrm{R}_{1}-4,980 \mathrm{~T}_{3}+0,151 \mathrm{~T}_{6}$ & $0,76^{* *}$ \\
\hline
\end{tabular}

n.s. Não significativo a $5 \% *$ Significativo a $5 \% * *$ Significativo a $1 \%$.

Ciência Rural, v.43, n.2, fev, 2013. 
(Tabela 2), mostraram-se mais importantes a $\mathrm{R}_{2}$ (radiação solar global média ocorrida da diferenciação da panícula até o início da floração) e a T 3 . SESHU \& CADY (1984) também obtiveram modelo com boa habilidade preditiva da produtividade de grãos, utilizando como variáveis preditoras a radiação solar global e a temperatura mínima do ar, ocorridas no período de maturação (30 dias após a floração). A influência da variável $\mathrm{R}_{2}$ na produtividade das cultivares do grupo médio está de acordo com a literatura, mas o mesmo caso não ocorre em relação a variável $\mathrm{R}_{1}$ e a produtividade das cultivares do grupo precoce. Os trabalhos de STANSEL (1975) e de YOSHIDA \& PARAO (1976) indicam que os maiores incrementos na produtividade, para níveis crescentes de radiação solar, são obtidos durante as fases reprodutiva e de maturação e que a fase vegetativa apresenta uma baixa resposta à radiação solar.

Para o grupo de cultivares de ciclo médio (Tabela 2 e Figura 1), quando analisada a regressão múltipla entre a produtividade, a temperatura mínima $\left(\mathrm{T}_{3}\right)$ e a radiação solar global $\left(\mathrm{R}_{2}\right)$, essa última com um valor fixado, obtém-se um decréscimo de $0,802 \mathrm{t} \mathrm{ha}^{-1} \mathrm{a}$ cada grau de temperatura mínima. Por exemplo, com um valor médio de radiação solar global de $500 \mathrm{cal} \mathrm{cm}^{-2} \mathrm{dia}^{-1}$ ocorrido desde a diferenciação da panícula ao início da floração $\left(\mathrm{R}_{2}\right)$ e valores de temperatura mínima do início da floração à maturação completa dos grãos $\left(\mathrm{T}_{3}\right)$, variando o intervalo de 19 a $14^{\circ} \mathrm{C}$, obtiveram-se rendimentos de 7,912 a 3,902t ha ${ }^{-1}$ (decréscimo a uma taxa de $0,802 \mathrm{t} \mathrm{ha}^{-1} \mathrm{a}$ cada ${ }^{\circ} \mathrm{C}$ ), respectivamente. Esses resultados divergem dos obtidos por SESHU \& CADY (1984), que indicaram aumentos de produtividade para valores fixos de radiação solar global, com a diminuição da temperatura mínima do ar. A provável explicação é que no trabalho de SESHU \& CADY (1984) a temperatura mínima do ar era mais elevada, sendo, na maioria das localidades, maior do que $20^{\circ} \mathrm{C}$, atingindo até $29,2^{\circ} \mathrm{C}$. No presente trabalho, as médias das temperaturas mínimas do ar foram, na quase totalidade dos períodos de desenvolvimento da planta, considerados inferiores a $20^{\circ} \mathrm{C}$, sendo que a menor média obtida foi de $14,7^{\circ} \mathrm{C}$. Além disso, SESHU \& CADY (1984) consideraram o período de 30 dias após a floração, enquanto que, neste trabalho, considerou-se o período de início da floração até a maturação $\left(\mathrm{T}_{3}\right)$, incluindo, portanto, o período da floração sensível às baixas temperaturas do ar (YOSHIDA, 1981).

Ao fixar-se um valor médio de temperatura mínima de $17^{\circ} \mathrm{C}$, do início da floração à maturação completa dos grãos $\left(\mathrm{T}_{3}\right)$ e considerando valores de radiação solar global variando entre 350 a $550 \mathrm{cal} \mathrm{cm}^{-2}$ $\mathrm{dia}^{-1}$ para o período $\mathrm{R}_{1}$ (grupo precoce, Tabela 1) e $\mathrm{R}_{2}$ (grupo médio, Tabela 2 e Figura 1), os valores de produtividade foram de 0,219 a 7,099 $\mathrm{tha}^{-1}$ (acréscimo a uma taxa de $1,72 \mathrm{t} \mathrm{ha}^{-1}$ a cada $50 \mathrm{cal} \mathrm{cm}^{-2} \mathrm{dia}^{-1}$ ) e de 5,528 a $6,658 \mathrm{t} \mathrm{ha}^{-1}$ (acréscimo a uma taxa de $0,28 \mathrm{tha}^{-1}$ a cada $\left.50 \mathrm{cal} \mathrm{cm}^{-2} \mathrm{dia}^{-1}\right)$, respectivamente, para os grupos precoce e médio. Esses resultados indicam que, para o grupo precoce, a radiação solar global foi mais relevante do que para o grupo médio.

Quando a variável preditora $\mathrm{T}_{6}$ (médias das temperaturas mínimas ocorridas do início da floração até a maturação dos grãos, elevada ao quadrado) foi acrescentada aos modelos dos dois grupos de cultivares (precoce e médio), a contribuição na precisão preditiva foi mínima, de apenas $4 \%$ e $0 \%\left(\mathrm{r}^{2}\right)$, respectivamente, como pode ser observado nas tabelas 1 e 2. Por isso, é recomendável indicar o uso dos modelos de regressão linear múltipla com as duas variáveis citadas $\left(R_{1}\right.$ e $T_{3}, R_{2}$ e $\left.T_{3}\right)$, pois, além de esses

Tabela 2 - Análise de regressão linear simples e múltipla entre a produtividade média de grãos de cultivares de arroz irrigado de ciclo médio, a radiação solar global (R) e a temperatura mínima do ar (T), em diferentes períodos do ciclo da planta, nas safras 2004/05, 2005/06 e 2006/07. Capão do Leão, RS.

\begin{tabular}{lll}
\hline Variável & Modelo & $\mathrm{r}^{2}$ \\
\hline $\mathrm{R}_{1}$ & $\mathrm{Y}=-34,829+0,081 \mathrm{R}_{1}$ & $0,71^{* *}$ \\
$\mathrm{R}_{2}$ & $\mathrm{Y}=-4,626+0,024 \mathrm{R}_{2}$ & $0,74^{* *}$ \\
$\mathrm{R}_{3}$ & $\mathrm{Y}=0,444+0,016 \mathrm{R}_{3}$ & $0,50^{* *}$ \\
$\mathrm{R}_{4}$ & $\mathrm{Y}=-6,986+0,030 \mathrm{R}_{4}$ & $0,66^{* *}$ \\
$\mathrm{~T}_{1}$ & $\mathrm{Y}=-8,856+0,827 \mathrm{~T}_{1}$ & $0,08^{\text {n.s. }}$ \\
$\mathrm{T}_{2}$ & $\mathrm{Y}=23,019-0,902 \mathrm{~T}_{2}$ & $0,0^{\text {n.s. }}$ \\
$\mathrm{T}_{3}$ & $\mathrm{Y}=-12,193+1,066 \mathrm{~T}_{3}$ & $0,82^{* *}$ \\
$\mathrm{R}_{2}, \mathrm{~T}_{3}$ & $\mathrm{Y}=-10,826+0,007 \mathrm{R}_{2}+0,802 \mathrm{~T}_{3}$ & $0,83^{* *}$ \\
$\mathrm{R}_{2}, \mathrm{~T}_{3}, \mathrm{~T}_{6}$ & $\mathrm{Y}=-4,343+0,007 \mathrm{R}_{2}+0,027 \mathrm{~T}_{3}+0,023 \mathrm{~T}_{6}$ & $0,83^{* *}$ \\
\hline
\end{tabular}

n.s. Não Significativo a 5\% ** Significativo a $1 \%$. 


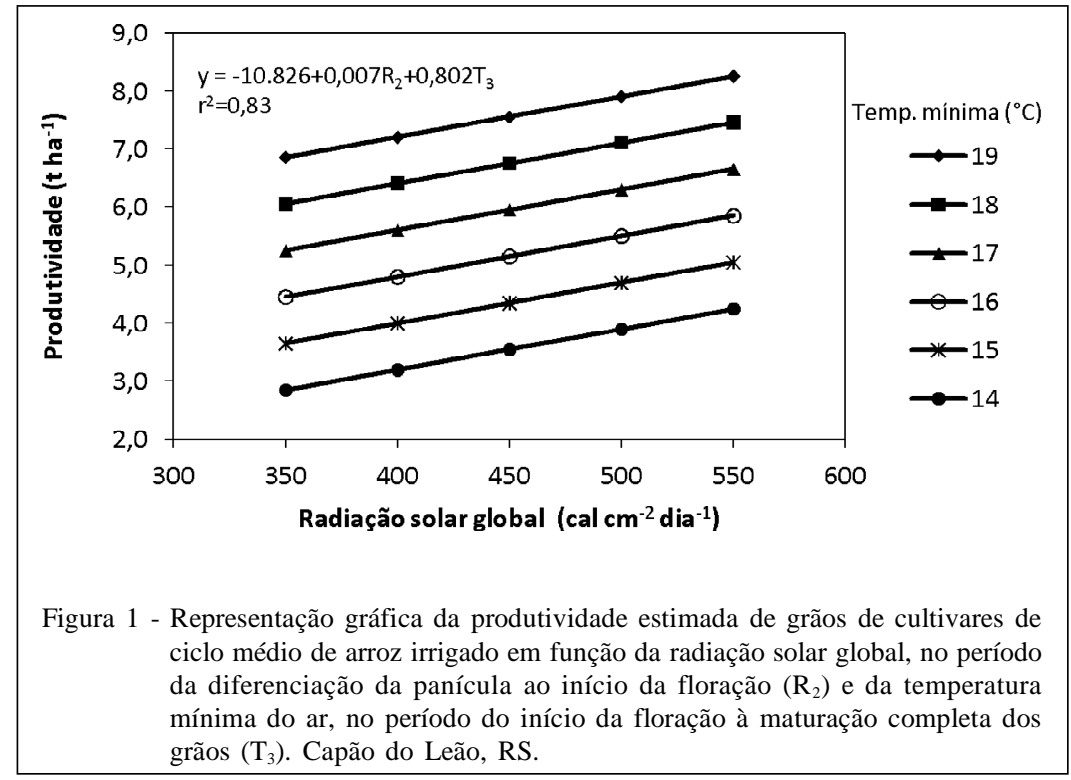

modelos terem boa representatividade $\left(\mathrm{r}^{2}\right)$, são os mais simples, propriedades recomendadas pelo processo de modelagem.

\section{CONCLUSÃO}

Modelos de regressão que utilizam como variáveis preditoras a radiação solar global e a temperatura mínima do ar, em diferentes períodos de desenvolvimento da planta, mostram-se adequados para a estimativa da produtividade de grãos de arroz irrigado.

Para as cultivares de ciclo médio, as melhores estimativas de produtividade são obtidas através do modelo de regressão linear múltipla, cujas variáveis preditoras são $\mathrm{R}_{2}$ (radiação solar global média, ocorrida da diferenciação da panícula até o início da floração) e $\mathrm{T}_{3}$ (média da temperatura mínima do ar ocorrida do início da floração até a maturação completa dos grãos).

\section{REFERÊNCIAS}

BAKEMA, A.H.; JANSEN, D.M. Using a simulation model to evaluate weather effects. In: INTERNATIONAL WORKSHOP ON THE IMPACT OF WEATHER PARAMETERS ON GROWTH AND YIELD OF RICE, 1986, Los Baños. Weather and rice, proceedings... Los Baños: IRRI, 1986. p.283-290.

CARMONA, L. de C. et al. Relação entre elementos meteorológicos e rendimento do arroz irrigado no Estado do Rio Grande do Sul. Revista Brasileira de Agrometeorologia, Santa Maria, v.10, n.2, p.289-294. 2002.

CONAB. Séries históricas: grãos. Maio/2011. Disponível em: <http://www.conab.gov.br/conteudos.php?a=1252\&t=2〉. Online. Acesso em: 18 maio, 2012.
COUNCE, P.A. et al. A uniform, objective, and adaptive system for expressing rice development. Crop Science, Madison, v.40, n.2, p.436-443, 2000. Disponível em: <https:// www.crops.org/publications >. Acesso em: 15 mar. 2012. doi: $10.2135 /$ cropsci2000.402436x.

DEIBLER, A.N. et al. Análise de parâmetros meteorológicos de ensaios de épocas de semeadura de arroz irrigado em Cachoeirinha, RS. Revista Científica Rural, Bagé, v.12, n.2, p.106-112, 2007.

KANDIANNAN, K. et al. A crop-weather model for prediction of Rice (Oryza sativa L.) yield using an empirical-statistical technique. Journal of Agronomy \& Crop Science, Berlin, v.188, n.1, p.59-62, 2002. Disponível em: <http://onlinelibrary. wiley.com>. Acesso em: 15 mar. 2012. doi: 10.1046/j.1439037x.2002.00533.x.

MOTA, F.S. Influência da radiação solar e do "frio" no período reprodutivo sobre o rendimento do arroz irrigado em Pelotas e Capão do Leão. Lavoura Arrozeira, Porto Alegre, v.47, n.413, p.22-23, 1994.

MURATA, Y. Estimation and simulation of rice yield from climatic factors. Agricultural Meteorology, Amsterdam, v.15, p.117-131, 1975.

NISHIYAMA, I. et al. Protecting effect of temperature and depth of irrigation water from sterility caused by cooling treatment at the meiotic stage of rice plants (In Japanese). Proceedings of the Crop Science Society of Japan, v. 38 , n.3, p.554-555, 1969.

PEDRO JÚNIOR, M.J. et al. Estimativa da produtividade de arroz irrigado por inundação em função da temperatura do ar e da radiação solar na região de Pindamonhangaba - SP. Scientia Agrícola, Piracicaba, v.52, n.1, p.96-100, 1995.

SANTOS, H.G. dos et al. Sistema brasileiro de classificação de solos. 2.ed. Rio de Janeiro: Embrapa Solos, 2006. 306p. 
SATAKE, T. Sterile-type cool injury in paddy rice plants. In: INTERNATIONAL RICE RESEARCH INSTITUTE, 1976, Los Baños. Climate and rice, proceedings... Los Baños: IRRI, 1976. p.281-300.

SESHU, D.V.; CADY, F.B. Response of rice to solar radiation and temperature estimated from international yield trials. Crop Science, Madison, v.24, n.4, p.649-654, 1984. Disponível em: <https://www.crops.org/publications>. Acesso em: 15 mar. 2012. doi: 10.2135/cropsci1984.0011183X002400040006x.

SOCIEDADE SUL-BRASILEIRA DE ARROZ IRRIGADO. Arroz irrigado: recomendações técnicas da pesquisa para o Sul do Brasil. Santa Maria: SOSBAI, 2005. 159p.

STANSEL, J.W. Effective utilization of sunlight. In: SIX DECADES OF RICE RESEARCH IN TEXAS. Beaumont: Texas Agricultural Experiment Station, 1975. p.43-50.

STEINMETZ, S.; BRAGA, H.J. Zoneamento de arroz irrigado por épocas de semeadura nos estados do Rio Grande do Sul e de Santa Catarina. Revista Brasileira de Agrometeorologia, Santa Maria, v.9, n.3, p.429-438, 2001.
TERRES, A.L.; GALLI, J. Efeitos do frio em cultivares de arroz irrigado no Rio Grande do Sul. In: EMBRAPA. Centro de Pesquisa Agropecuária de Terras Baixas de Clima Temperado (Pelotas, RS). Fundamentos para a cultura do arroz irrigado. Campinas: Fundação Cargill, 1985. Cap.6, p.83-94.

WREGE, M.S. et al. (Ed.) Atlas climático da Região Sul do Brasil: Estados do Paraná, Santa Catarina e Rio Grande do Sul. Pelotas: Embrapa Clima Temperado; Colombo: Embrapa Florestas, 2011. 211p.

YOSHIDA, S. Fundamentals of rice crop science. Los Baños: IRRI, 1981. 269p.

YOSHIDA, S.; PARAO, F.T. Climatic influence on yield and yield components of lowland rice in the tropics. In: INTERNATIONAL RICE RESEARCHE INSTITUTE, 1976, Los Baños. Climate and Rice, proceedings... Los Baños: IRRI, 1976. p.471-494.

ZONTA, E.P.; MACHADO, A.A. Sistema de análise estatística para microcomputadores. Pelotas: UFPel. 1984. 75p. 